\title{
Current Treatment Options for Bilateral Vocal Fold Paralysis: A State-of-the-Art Review
}

\author{
Yike Li · Gaelyn Garrett · David Zealear \\ Department of Otolaryngology, Vanderbilt University Medical Center, Nashville, TN, USA
}

Vocal fold paralysis (VFP) refers to neurological causes of reduced or absent movement of one or both vocal folds. Bilateral VFP (BVFP) is characterized by inspiratory dyspnea due to narrowing of the airway at the glottic level with both vocal folds assuming a paramedian position. The primary objective of intervention for BVFP is to relieve patients' dyspnea. Common clinical options for management include tracheostomy, arytenoidectomy and cordotomy. Other options that have been used with varying success include reinnervation techniques and botulinum toxin (Botox) injections into the vocal fold adductors. More recently, research has focused on neuromodulation, laryngeal pacing, gene therapy, and stem cell therapy. These newer approaches have the potential advantage of avoiding damage to the voicing mechanism of the larynx with an added goal of restoring some physiologic movement of the affected vocal folds. However, clinical data are scarce for these new treatment options (i.e., reinnervation and pacing), so more investigative work is needed. These areas of research are expected to provide dramatic improvements in the treatment of BVFP.

Keywords. Vocal Cord Paralysis; Synkinesis; Recurrent Laryngeal Nerve Injuries; Electric Stimulation Therapy; Botulinum Toxins

\section{INTRODUCTION}

The term vocal fold paralysis (VFP) refers to the reduced or absent function of the vagus nerve or its distal branch, the recurrent laryngeal nerve (RLN) [1-3]. The most common causes include laryngeal or extralaryngeal cancers, iatrogenic injury during neck, thyroid gland, or chest surgery, and various neurogenic conditions (e.g., amyotrophic lateral sclerosis and closed head injury) [3-6]. The incidence of the bilateral VFP (BVFP) comprises about one third of allVFP cases [4]. Compared with unilateral VFP (UVFP), where normal ventilation can be relatively spared, the classical presentation of patients with BVFP is reduction of the glottal area resulting in various degrees of airway compromise. Patients will have noisy inspiratory breathing primarily with minimal voice change.

Acute bilateral VFP caused by iatrogenic nerve injury after

- Received February 15, 2017

Revised June 2, 2017

Accepted June 19, 2017

- Corresponding author: Yike Li

Department of Otolaryngology, Vanderbilt University Medical Center, 602 Oxford House, 1313 21st Avenue South Nashville,TN 37232-4480, USA

Tel: +1-615-335-8146, Fax: +1-615-936-6914

E-mail: yike.li.1@vanderbilt.edu thyroid or other surgery can result in immediate symptoms in the recovery room requiring urgent airway intervention. In other cases, the airway symptoms can worsen over several weeks as a result of aberrant reinnervation or synkinesis. As the motor fibers in the RLN innervate both abductor and adductor muscles of the vocal fold, damage to the RLN compromises both abducting and adducting functions as a consequence of laryngeal muscle denervation. In most of these patients, random regeneration of neural fibers in the RLN results in aberrant reinnervation of laryngeal muscles. In such a synkinetic larynx, contraction of abductor and adductor antagonists produces ineffective, unsynchronized or even opposite movement of the vocal fold(s) [7]. Since the number of adductor muscle fibers are approximately 4 times greater than the number of abductor muscle fibers, it is anticipate bead that the adductors will receive greater reinnervation by any motoneuron type, including both glottal closure and opener motoneurons. This is the reason the vocal folds tend to assume a paramedian position statically. When the involvement of vocal folds is bilateral, patients end up with severe airway compromise and require timely intervention.

The primary objective of intervention for BVFP is to improve patients' ventilation. Various surgical procedures have been developed to address the airway restriction seen with BVFP. Tra-

Copyright @ 2017 by Korean Society of Otorhinolaryngology-Head and Neck Surgery.

This is an open-access article distributed under the terms of the Creative Commons Attribution Non-Commercial License (http://creativecommons.org/licenses/by-nc/4.0)

which permits unrestricted non-commercial use, distribution, and reproduction in any medium, provided the original work is properly cited. 
cheostomy remains the most commonly used procedure in the early onset period when nerve recovery is still hopeful. Although tracheostomy has its obvious downsides for patients, it provides the largest airway and maintains the structural integrity of the glottic larynx. Since the beginning of the 20th century, other approaches to enlarge the stenotic airway have been introduced, first with external methods and later with endoscopic techniques. In addition, new techniques such as laryngeal pacing and reinnervation procedures have also been studied and applied in some cases of BVFP [8,9]. In recent years, botulinum toxin (Botox) injection has been used in patients with laryngeal synkinesis. Other treatment approaches currently being investigated include gene therapy and stem cell therapy. These various treatment options are reviewed below.

\section{TRACHEOSTOMY}

Tracheostomy is one of the most common surgical interventions for BVFP. Despite its effectiveness, tracheostomy is now becoming less favored by most patients because it presents an open wound that requires long-term care and creates psychosocial problems [9]. Patients experience decreased quality of life and must engage in continual postoperative management of their tracheostomies $[10,11]$. Recent evidence has shown tracheostomy is less cost-effective compared to endoscopic techniques (i.e., cordotomy and arytenoidectomy) in management of BVFP [12]. Nevertheless, tracheostomy is still indicated as an effective, emergent, and initial method for management of BVFP over the short term [13].

\section{ARTENOIDECTOMY}

The arytenoid cartilage is a key structure of the posterior glottis. Removal of arytenoid cartilage (i.e., arytenoidectomy) is a permanent and irreversible surgical procedure, by which the glottal inlet is expanded in its transverse axis, providing a larger airway for respiration [8]. Arytenoidectomy is widely used either alone or in combination with partial resection of the vocal fold (i.e., arytenoid cordectomy).

Resection of the arytenoid cartilage had been performed through an open-neck approach since early 1900s [8,14-18]. In

\section{H I G H L I G H T S}

- Patients with bilateral vocal fold paralysis are dyspneic and require timely intervention.

- The primary goal is to improve patients' ventilation. Surgery is the mainstream of treatment.

- Current treatment options are reviewed in this article.
1948, Thornell [19] described the first endolaryngeal arytenoidectomy through the endoscopic approach. His technique later became the most widely accepted strategy for endoscopic arytenoidectomy. A temporary tracheostomy was used in the early perioperative period with his approach. The glottis is widened by partial mucosal resection over the arytenoid area extending into the aryepiglottic fold. This technique, along with its various modifications $[14,20]$, demonstrated good results in terms of ventilatory improvement in patients with BVFP [21]. Arytenoidectomy was further advanced by application of lasers in surgery. The major advantage of using the $\mathrm{CO}_{2}$ laser include the precision of laser incision, the capacity to maintain hemostasis, and decreased postoperative edema [22,23]. In 1983, Ossoff et al. [24] first described the total arytenoidectomy procedure using the $\mathrm{CO}_{2}$ laser endoscopically. In Ossoff's technique, after ablation of the majority of the arytenoid, the incision was extended laterally to induce fibrosis, which retracted the vocal fold laterally $[8,24]$. Modifications to Ossoff's technique have been reported by other clinicians $[25,26]$. In particular, Crumley [27] proposed endoscopic laser medial arytenoidectomy with minimal resection of the vocal fold. In this technique, a resection of the medial part of the arytenoid body was performed by preserving other aspects of the cartilage, including vocal process. This aimed to provide maximal preservation of the phonatory structures. Nonetheless, deterioration in voice quality was documented in a great proportion of patients $[22,28,29]$. In addition, arytenoidectomy was susceptible to granuloma and scar formation, which led to re-narrowing of the airway. In this case, one or more revision surgeries were usually required [8]. In comparison with other extralaryngeal techniques to perform arytenoidectomy, endoscopic laser resections did not differ significantly in terms of functional outcomes, but had a significant advantage that tracheostomy was not required [8]. Avoidance of tracheostomy or successful decannulation could be achieved in the majority of patients [29,30]. Use of an endoscopic plasma coblator instead of laser induced less scar formation by avoiding thermal damage to surrounding tissues [31], but a large-scale patient study with this technique has not been performed.

\section{CORDOTOMY}

Like arytenoidectomy, cordotomy (i.e., posterior cordotomy and transverse cordotomy) is another irreversible surgical approach that aims at enlargement of the airway aperture at the glottic level by excision of tissues. Cordotomy is different from arytenoidectomy in that the former approach aims at resection of laryngeal soft tissues, such as parts of the vocal fold, the vocal ligament, or the thyroarytenoid (TA) muscle [8]; while the latter approach mainly focuses on arytenoid cartilage ablation. Sometimes they are performed conjointly (i.e., arytenoidcordectomy).

Resection of a large portion of the vocal fold was performed 
as a treatment approach for BVFP as long as a century ago. Soon thereafter, dissection focused on the sub-mucosa to preserve the overlying mucosa and minimize subsequent scar formation and voice disturbance [8]. After the introduction of a transoral approach for laser arytenoidectomy [24], Dennis and Kashima [32] followed suit with their introduction of a modern endoscopic laser cordotomy technique in 1989 . They performed the $\mathrm{CO}_{2}$ laser posterior cordotomy by resecting the soft tissues of the posterior vocal fold and transecting the conus elasticus. In this technique, a C-shaped wedge of posterior vocal fold was excised from the free border with a lateral extension of a couple millimeters to release soft tissue tension on the vocal fold [8]. Improved ventilation was achieved in most patients with BVFP following cordotomy [32-35]. Over $60 \%$ of patients were decannulated [32, 34,35]. Like arytenoidectomy, however, cordotomy was susceptible to granulation and scar formation. It was reported that bilateral or revision cordotomies were needed in about $30 \%$ of patients due to decreased glottal opening from formation of scar tissue or granulation $[9,32,33]$. Another most commonly seen side effect associated with cordotomy was deterioration of voice quality [34-36]. Patients often complained of a rough and breathy voice because of damage to the vibratory part of the operated vocal fold [37].

Laser endoscopic cordotomy has become the preferred therapeutic intervention for long-term management of BVFP. In comparison to arytenoidectomy, cordotomy is preferred because it is less destructive and there is less tendency for aspiration. Cordotomy can be proposed as an alternative to tracheostomy even at the time of diagnosis. However, it should be emphasized that the level of ventilation permitted through a cordotomy is usually less than that through a tracheostomy. Further, vocal fold resection impairs voice quality and puts the patient at some risk for aspiration. In addition, revision interventions are often required due to granulation or formation of scar tissue, which retract the vocal fold to the median position $[8,9]$. Although cordotomy has been modified by otolaryngologists to improve patients' ventilation and maximize the preservation of their voice quality, this treatment approach is less than ideal [36,37].

\section{LATEROFIXATION OFTHE VOCAL FOLD AND/ ORTHE ARYTENOID CARTILAGE}

Laterofixation (i.e., suture laterofixation and suture lateralization) of the arytenoid and/or the attached vocal fold using a combination of endoscopic and external means has emerged as an alternative surgical approach for BVFP [38]. In recent years, it has been performed in adult and pediatric patients with good success rates $[39,40]$. Due to its reversible nature, laterofixation is favored by many BVFP patients as a temporary management of the airway, based on the fact that spontaneous recovery could be expected in $40 \%-86 \%$ of cases if the RLNs have not been transected $[8,41]$.
According to a review by Sapundzhiev et al. [8], Rethi reported the lateralization of arytenoid through a laryngofissure dissection in 1922. Ejnell and his associates [42,43] performed suture lateralization using a small endotracheal tube without the need for a tracheostomy. In this technique, the larynx was exposed by direct laryngoscopy and the cricoarytenoid joint assessed by palpation. After removal of the TA muscle, sutures were introduced into the larynx through 2 needles inserted from outside. The sutures were pulled out through the laryngoscope and knotted to lateralize the vocal fold [44]. In 1983, Lichtenberger $[40,45]$ introduced a needle carrier capable of passing a needle and suture endolaryngeally through the thyroid ala to the skin, thereby significantly simplifying the procedure. Specifically, following endoscopic exposure of the larynx, a longitudinal incision was made on the superior surface of the vocal fold and the TA muscle was removed. Using a curved tip needle carrier, one end of the suture was pushed through the larynx below the posterior third of the vocal fold and the other end was pushed through above the vocal fold. Both ends of the fixation suture were pulled and knotted over the strap muscles. A second lateral fixation suture was placed 1-2 $\mathrm{mm}$ anterior to the first suture using the same technique. Over past years there have been several procedural modifications to this technique $[36,46-$ 52]. In particular, Woodson and Weiss [53] and Woodson [54] proposed their technique called "arytenoid abduction." This technique is based upon the fact that residual muscle motion is often partially preserved in adductor muscles following RLN injury, as adductor motor fibers are 4 times more plentiful than the abductor fibers in the RLN [2]. Their technique is to perform suture laterofixation of the arytenoid cartilage, which provides posterior-caudal traction (simulating the contraction of the posterior cricoarytenoid [PCA] muscle) to abduct the vocal fold. Meanwhile, closure of the glottis during phonation and swallowing can be achieved by voluntary control of the adductor muscles [54]. This technique, although relies primarily on the recovery of adductor function, is still a promising intervention that can restore dynamic motion of the paralyzed larynx [53].

Laterofixation can be performed independently or coupled with other endoscopic procedures, such as arytenoidectomy $[46,47,55]$. Compared to static procedures (i.e., cordotomy and arytenoidectomy), enlargement of glottal opening and improvement of aerodynamic measures are significantly greater in patients following laterofixation. In addition, laterofixation provides better phonatory closure of the vocal folds that perhaps leads to better voice quality [36,39,54]. Risk of aspiration appears to be low $[48,54,56]$. The rate of re-operation was reported to range from $10 \%-30 \%[40,50,52]$.

Suture laterofixation is potentially reversible so that it may serve as an alternative to tracheostomy. Lateralization of vocal fold and/or arytenoid cartilage enlarges the airway without damaging phonatory tissues, thus preserving the option of voice restoration by reversal of the procedure. It can be applied bilat- 
erally or with other endoscopic procedures as needed [57]. The incidence of adverse events (e.g., hoarseness, aspiration, dysphagia, and revision surgery) are relatively low compared with other static procedures. Arytenoid abduction may even preserve the dynamic motion of the larynx. In all, suture laterofixation is indicated for patients with BVFP when recovery of laryngeal function is expected or avoidance of tracheostomy is preferred [39].

\section{REINNERVATION}

No glottic enlargement techniques based on resection restore both major functions of the larynx, specifically, enlarging the airway for inspiration and closing it for vocalization and swallowing. In this regard, procedures for reinnervating laryngeal muscle have been investigated to restore the voluntary motion of the larynx. In fact, the primary goal should be to re-establish the vocal fold abduction through reinnervation of the abductor (PCA) muscle, as dyspnea is the major symptom in most of these patients whose adducting function is partially preserved. Laryngeal reinnervation, although developed primarily for treatment of UVFP, may also be applied in BVFP patients.

Anastomosis of the RLN was reported about a century ago [58], but there have been limited studies in this area, possibly due to the variability and complexity of nerve supply [59]. Results of human trials are sparse and only based on case series. Miehlike [60] developed a technique for RLN anastomosis in animal studies and subsequently applied it to the human. In this technique, the distal posterior RLN branch innervating the PCA muscle was transected and anastomosed with the main funiculus of the RLN dissected out of the vagus trunk and transected. The distal anterior RLN branch innervating the adductor muscles was then transected [59]. However, this technique has not been further explored by other researchers, possibly due to its complexity in practice.

Attempts have also been made using foreign nerves to reinnervate the PCA muscle. Phrenic nerve is a good source of nerve supply as it contains a homogeneous composition of motoneurons that are active during inspiration [59]. A recent study from China was conducted in 44 patients with BVFP to assess the efficacy of PCA muscle reinnervation using the left phrenic nerve [61]. Results seemed promising in that inspiratory vocal fold abduction was achieved in 41 cases (93\%). Although the patients suffered from hemi-diaphragm paralysis, they had substantial recovery of diaphragm motion $(40 \%-82 \%)$ and respiratory function within 1 year. Marina et al. [59] further demonstrated that phrenic nerve roots innervating the diaphragm were mainly distributed in C3-C5. Therefore, only a branch of the phrenic nerve may be taken to minimize loss of diaphragm motion and respiratory capacity.

Perhaps the most explored and applied reinnervation procedure is transplanting an active nerve-muscle pedicle to the PCA muscle harvested from an accessory muscle of inspiration (i.e., omohyoid or sternohyoid) [8]. Increased glottic airway was observed in over $80 \%$ of patients, presumably because the transferred nerve-muscle pedicle was activated during hypoxic conditions [62,63].

In summary, laryngeal reinnervation appeared to be a promising surgical approach for BVFP patients. However, the evidence of success in humans is limited, thus more clinical trials are needed before any other conclusion may be drawn.

\section{LARYNGEAL PACING AND FUNCTIONAL ELECTRICAL STIMULATION}

Functional electrical stimulation (FES) of paralyzed laryngeal muscles has been investigated over the last 4 decades [64-66]. In 1977, Zealear and Dedo [64] first introduced the concept of FES of paralyzed head, neck and thorax muscles. Their model was the unilaterally paralyzed cricothyroid muscle of the canine. Subsequently, this idea was translated to stimulation of the paralyzed PCA muscles in the canine model of BVFP, termed laryngeal pacing $[65,67,68]$. It was then shown in BVFP canines chronically implanted with stimulators, that bilateral PCA activation could restore ventilation and exercise tolerance to normal without any aspiration over the long term [69,70]. Zealear et al. [66] first confirmed laryngeal pacing was an effective means of treatment in the human using an external device. Shortly thereafter, his team conducted the first human trial of unilateral laryngeal pacing in 7 patients with BVFP implanted with a commercial stimulator and electrodes [71]. Results demonstrated that unilateral pacing was an effective treatment superior to posterior cordotomy with respect to postoperative ventilation and voice outcome measures [37]. Mueller and his associates $[72,73]$ recently conducted a clinical trial of unilateral pacing in 9 patients with BVFP. They used minimally invasive electrodes activated by an external pacemaker affixed to the chest wall. Significant improvement in ventilation with no negative effect on voice quality was noted.

In summary, these animal trials and pioneer clinical cases demonstrated clearly the feasibility of FES in the treatment BVFP. Future studies may involve a multicenter clinical trial of laryngeal pacing.

\section{BOTULINUMTOXIN}

Botox is a neurotoxin produced by the Clostridium botulinum. There are 7 serologically distinct toxin types (A-G). Type A and $\mathrm{B}$ are the forms most frequently used clinically. The toxin prevents the release of acetylcholine from axon terminals and thus causes flaccid paralysis [74]. It was first introduced for medical use in the 1980s [75]. In case of BVFP, Botox may be used to 
block aberrant reinnervation of the adductor muscles by inspiratory motoneurons. In this way, the abductor inspiratory motoneurons would gain advantage and become more effective in producing glottal opening $[74,76]$.

Marie et al. [77] first described a case of Botox injection into bilateral adductor muscles as a treatment for BVFP. Improvement in ventilation was seen in this patient. Zealear et al. [76] also used Botox in their study of human laryngeal pacing to counteract the stimulated adduction of the vocal fold due to spread of stimulus current. They also noted an increase in the unstimulated passive airway with an improvement in ventilation due to blockade of the adductor muscles. A subsequent study of adductor muscle Botox injection in 11 BVFP patients demonstrated symptomatic improvement in ventilation with breathy dysphonia [78]. The reported dosage was at least 2.5 mouse units for each vocal fold. Overall, Botox injection appeared to provide an acceptable, but temporary (around 3 months) improvement in glottal opening [76]. Therefore, with repeated injections, patients may enjoy ventilatory improvement over a longer period of time. Additional studies are needed to compare the outcome of Botox injection with that achieved by other surgical interventions [74].

\section{NEUROMODULATORY EFFECT OF ELECTRICAL STIMULATION IN PROMOTING SELECTIVE REINNERVATION OF THE DENERVATED PCA MUSCLE IN BVFP}

Electrical stimulation has emerged as a potential therapeutic measure following peripheral nerve injury. It has long been established that electrical stimulation improves functional recovery of denervated muscles by accelerating axon regeneration and reinnervation of muscle before significant atrophy occurs [79-85]. More recent evidence has revealed that electrical stimulation may also promote the specificity of reinnervation of denervated laryngeal muscles. This is an important finding since $70 \%$ of BVFP patients become synkinetically paralyzed despite successful reinnervation. Zealear et al. [86] first showed that synkinesis could be avoided by stimulating the muscle or its reconnecting motoneurons in the canine. In a second study $[86,87]$, quantitative evidence was obtained demonstrating that low frequency stimulation of the PCA muscle repressed reconnection by foreign reflex glottic closure (RGC) motoneurons and promoted reinnervation by native inspiratory motoneurons. In a subsequent study using a canine model of BVFP, low frequency stimulation (i.e., $10 \mathrm{~Hz}$ ) of denervated PCA muscles was shown to improve functional recovery. Specifically, the selective reinnervation of muscles minimized paradoxical closure of the glottis during inspiration and restored exercise tolerance to normal [88]. EMG recordings showed a near normal pattern of low PCA and high TA reinnervation by RGC motoneurons in $10 \mathrm{~Hz}$ animals. In contrast, nonstimulated controls and $40 \mathrm{~Hz}$ stimulated animals had faulty reinnervation, severe paradoxical closure of the glottis during hypercapnia, and poor tolerance to exercise. Such findings may offer a physiologic and natural approach to treatment of BVFP. It should encourage further investigation of FES neuromodulation to improve voluntary function and avoid synkinesis by stimulating the PCA muscle during a critical period of regeneration following RLN injury.

\section{GENE THERAPY}

Gene therapy for BVFP presents the idea of delivering genes to the injured neurons and/or denervated muscles, thus enhancing the regrowth of these damaged neurons and rejuvenating laryngeal muscles. These genes typically encode neurotrophic factors that promote neuronal survival, or growth factors stimulating muscle cell proliferation and differentiation [89]. The therapeutic genes are delivered by vectors injected into the RLN or laryngeal muscles. There they are absorbed by the muscle cells, or by the neuronal cell bodies via retrograde axonal transport [90-92]. After these genes are transduced into the nucleus of the target cells, they produce peptides that promote RLN regeneration, synaptic formation, and muscle growth.

Preliminary attempts have been made to investigate the effect of gene therapy for RLN injury in animal models. Shiotani and his associates [93-95] have investigated insulin-like growth factor I gene transfer in rats' denervated larynges. They injected the gene using a polyvinyl-based delivery system into the denervated TA muscle. Compared to the controls, treated animals demonstrated a significant increase in the diameter of muscle fibers and the percentage of end plates contacting axons in the TA muscle [93-95]. In a subsequent study in rat, they injected an adenoviral vector encoding glial cell line-derived neurotrophic factor (GDNF) into nucleus ambiguus following vagus nerve transection. The treated animal demonstrated a significant reduction in the loss of nucleus ambiguus motoneurons at 4 weeks after injection. The GDNF-gene treated animals also showed higher inhibition of nitric oxide synthase activity and better preservation of choline acetyltransferase immunoreactivity, both indicating greater recovery of nerve function [96]. Further, they injected adenoviral-tagged GDNF into the crushed RLN in a rat model. The treated animals had significantly improved nerve conduction velocity and higher percentage of vocal fold motion recovery up to 4 weeks. The treated rats also showed a significantly larger axonal diameter and improved remyelination over controls [97].

Currently, the major bottleneck of gene therapy in the treatment of BVFP is its null effect in preventing synkinesis [90]. In addition, study may also be needed to minimize neuronal damage by delivery of viral vectors into the CNS. As of now, this technique may potentially benefit patients with BVFP caused by neurodegenerative diseases. 


\section{STEM CELLTHERAPY}

Stem cell transplantation has been recognized as a therapy by allowing tissue regeneration. Stem cell therapy may offer improved healing potential in degenerative tissue. For instance, autologous stem cells can be isolated from small samples of tissue from patients, cultured to a critical mass and re-implanted. Muscle stem cells may promote regrowth of atrophic muscle mass and provide a better platform for reinnervation.

Halum et al. [98] introduced use of autologous muscle-derived stem cells (MSCs) for the treatment of VFP in 2007. They successfully isolated, cultured and labelled MSCs before injecting them into denervatedTA muscles in rats. These cells survived and were incorporated into the muscle alongside atrophying fibers at 2 months. This incorporation attenuated the overall muscle atrophy in comparison to non-treated controls. Two of 8 treated rats showed a weak vocal fold adduction upon activation of the glottal closure reflex, while none of the control animals exhibited such a response. Dirja et al. [99] explored the use of induced pluripotent stem (iPS) cells as an alternative to MSCs. The labeled iPS cells successfully differentiated into skeletal muscle cells in vitro. These cells were then transplanted into the atrophied TA muscle and survived for 2 weeks in rats. Gotoh's team injected adipose-derived regenerative cells into the denervated vocal fold of the pig. Remarkable hypertrophy of the TA muscle fiber was observed around the injection site at 1 month [100].

Table 1. Summary of treatment options for BVFP

\begin{tabular}{|c|c|c|c|}
\hline $\begin{array}{l}\text { Treatment modality } \\
\text { for BVFP }\end{array}$ & Indication & Pros & Cons \\
\hline Tracheostomy & $\begin{array}{l}\text { Acute dyspnea; temporary management } \\
\text { of BVFP }\end{array}$ & $\begin{array}{l}\text { Immediate relief of airway obstruction; greater } \\
\text { improvement of ventilation compared to static } \\
\text { procedures; no revision surgery required }\end{array}$ & $\begin{array}{l}\text { Destructive of normal tissues; psychosocial } \\
\text { impairment; scar formation; daily care of } \\
\text { open wound required; decreased quality } \\
\text { of life }\end{array}$ \\
\hline Arytenoidectomy & $\begin{array}{l}\text { Permantant management of BVFP; } \\
\text { patients who want to be decannulated } \\
\text { or avoid tracheostomy }\end{array}$ & $\begin{array}{l}\text { Quick, effective enlargement of glottis to return } \\
\text { breathing through mouth without dyscosmesis; } \\
\text { can be combined with cordotomy; more cost- } \\
\text { effective than tracheostomy }\end{array}$ & $\begin{array}{l}\text { Irreversible; deterioration of voice; scar or } \\
\text { granuloma formation; aspiration; may need } \\
\text { revision surgery }\end{array}$ \\
\hline Cordotomy & $\begin{array}{l}\text { Permantant management of BVFP; } \\
\text { patients who want to be decannulated } \\
\text { or avoid tracheostomy }\end{array}$ & $\begin{array}{l}\text { Quick, effective enlargement of glottis to return } \\
\text { breathing through mouth without dyscosmesis; } \\
\text { can be combined with arytenoidectomy; more } \\
\text { cost-effective than tracheostomy; less tendency } \\
\text { for aspiration than arytenoidectomy }\end{array}$ & $\begin{array}{l}\text { Irreversible; deterioration of voice; scar or } \\
\text { granuloma formation; aspiration; may need } \\
\text { revision surgery }\end{array}$ \\
\hline Laterofixation & $\begin{array}{l}\text { Temporary management of the airway, } \\
\text { with expectation of recovery of laryngeal } \\
\text { function or avoidance of tracheostomy }\end{array}$ & $\begin{array}{l}\text { Reversible; alternative to tracheostomy; greater } \\
\text { improvement of airway, better voice quality, } \\
\text { and less revision rate than arytenoidectomy } \\
\text { and cordotomy; may be performed with other } \\
\text { endoscopic procedures }\end{array}$ & $\begin{array}{l}\text { Complications such as hoarseness, need } \\
\text { for adjustment, remedialization, dysphagia } \\
\text { or aspiration }\end{array}$ \\
\hline Reinnervation & $\begin{array}{l}\text { Patients that have non-atrophic viable } \\
\text { muscles maintained through synkinetic } \\
\text { reinnervation }\end{array}$ & $\begin{array}{l}\text { A promising procedure that may allow return of } \\
\text { spontaneous vocal fold abduction; non-distruc- } \\
\text { tive and doesn't impair adductory functions }\end{array}$ & $\begin{array}{l}\text { Technically more difficult; human trials are } \\
\text { limited; potential diaphragmatic paralysis }\end{array}$ \\
\hline Laryngeal pacing & $\begin{array}{l}\text { Patients that have non-atrophic viable } \\
\text { muscles maintained through synkinetic } \\
\text { reinnervation }\end{array}$ & $\begin{array}{l}\text { Greater ventilatory improvement reported than } \\
\text { any other approach; no compromise of voice } \\
\text { or swallowing }\end{array}$ & $\begin{array}{l}\text { Still experimental with only } 2 \text { human trials; } \\
\text { complicated procedure; more expensive } \\
\text { than enlargement or lateralization } \\
\text { approaches; device has to be replaced } \\
\text { every 5-10 years }\end{array}$ \\
\hline Botox injection & $\begin{array}{l}\text { Temporary management of synkinetic } \\
\text { larynx }\end{array}$ & $\begin{array}{l}\text { Less invasive; short-term improvement in } \\
\text { ventilation; little effect on voice or swallowing }\end{array}$ & $\begin{array}{l}\text { Repeated injections are required; human } \\
\text { trials are limited }\end{array}$ \\
\hline Neuromodulation & $\begin{array}{l}\text { Recently injured RLNs; muscles still } \\
\text { denervated and nerve regenerating } \\
\text { prior to synkinetic reinnervation }\end{array}$ & $\begin{array}{l}\text { From canine studies, electrical neuromuscular } \\
\text { conditioning promotes selective reinnervation } \\
\text { of muscles, minimizes synkinesis and restores } \\
\text { ventilation to normal }\end{array}$ & Experimental; no human trial \\
\hline Gene therapy & $\begin{array}{l}\text { BVFP caused by neurodegenerative } \\
\text { diseases }\end{array}$ & $\begin{array}{l}\text { Less invasive; could promote nerve regeneration } \\
\text { and prevent muscle atrophy }\end{array}$ & $\begin{array}{l}\text { Experimental; no human trial; not effective } \\
\text { in preventing synkinesis; neuronal damage } \\
\text { by viral vectors }\end{array}$ \\
\hline Stem cell therapy & $\begin{array}{l}\text { BVFP caused by neurodegenerative } \\
\text { diseases }\end{array}$ & $\begin{array}{l}\text { Could promote nerve regeneration and prevent } \\
\text { muscle atrophy }\end{array}$ & $\begin{array}{l}\text { Experimental; no human trial; not effective in } \\
\text { preventing synkinesis; issues associated } \\
\text { with issolation, culture and survival of stem } \\
\text { cells }\end{array}$ \\
\hline
\end{tabular}

BVFP, bilateral vocal fold paralysis; Botox, botulinum toxin; RLN, recurrent laryngeal nerve. 
Similar to gene therapy, the application of stem cell therapy for BVFP is largely limited by its null effect in preventing synkinesis. So far little is known about its effect on the reinnervation pattern of laryngeal muscles. Further investigation is required before it can be considered as a treatment option for BVFP.

\section{SUMMARY}

The treatment options for BVFP are summarized in Table 1. Static glottis enlarging procedures, which function by either resection of laryngeal tissues (i.e., arytenoidectomy and cordotomy) or displacing anatomical structures (i.e., suture laterofixation of vocal fold or arytenoid abduction), are most commonly used as they provide an immediate effect of airway improvement regardless of the innervation status of laryngeal muscles. The common side effects associated with such procedures are dysphonia, dysphagia, and aspiration. Suture laterofixation of vocal fold is more favorable than the other static procedures in that it is reversible and minimally impairs adductor functions: voice and swallowing. Further, it may be considered as an alternative for tracheostomy for patients with good prognosis for spontaneous reinnervation. Other new techniques, such as reinnervation, laryngeal pacing and Botox injection, are still experimental. They are indicated in BVFP patients who have laryngeal muscle reinnervation that is synkinetic. Nevertheless, they provide promising therapies for the treatment of BVFP. Specifically, these techniques represent a more physiological approach to recovery of laryngeal function without necessitating tissue damage. Selective reinnervation of the PCA muscles by inspiratory motoneurons within a branch of the phrenic nerve represents a more natural approach to reverse synkinesis in BVFP. Further, neuromodulation of the reinnervation process by electrical stimulation has been shown to promote selective reinnervation by original motoneurons and avoid synkinesis altogether. Although the goal is to cure paralysis, no clinical trial has been conducted with this novel technique as yet.The emergence of gene therapy and stem cell therapy reflects new ideas in treatment for BVFP by promoting regrowth of neurons and atrophic muscles. However, both techniques are limited by their null effect in preventing synkinesis. Further study in both animals and humans will be needed to explore their potential benefits for BVFP. In the future, patients with BVFP are expected to benefit from the advancement of those new treatment approaches, and have a better quality of life.

\section{CONFLICT OF INTEREST}

Dr. Zealear has a conflict to disclose. An Food and Drug Adminstration (FDA) approved clinical trial of laryngeal pacing is in progress through a contract with St. Jude Medical Inc. As patent inventor and principal investigator on the project, Dr. Zealear will receive royalties on sales if the commercial phase is reached with this technology. Neither of the other authors have a conflict of interest.

\section{ACKNOWLEDGMENTS}

Special gratitude is given to Bernard Rousseau, $\mathrm{PhD}$ and Dan Ashmead, PhD for their discussion with the authors on the write-up of this review.

\section{REFERENCES}

1. Mueller AH. Laryngeal pacing for bilateral vocal fold immobility. Curr Opin Otolaryngol Head Neck Surg. 2011 Dec;19(6):439-43.

2. Zealear DL, Billante CR. Neurophysiology of vocal fold paralysis. Otolaryngol Clin North Am. 2004 Feb;37(1):1-23.

3. Hillel AD, Benninger M, Blitzer A, Crumley R, Flint P, Kashima $\mathrm{HK}$, et al. Evaluation and management of bilateral vocal cord immobility. Otolaryngol Head Neck Surg. 1999 Dec;121(6):760-5.

4. Benninger MS, Gillen JB, Altman JS. Changing etiology of vocal fold immobility. Laryngoscope. 1998 Sep;108(9):1346-50.

5. Misono S, Merati AL. Evidence-based practice: evaluation and management of unilateral vocal fold paralysis. Otolaryngol Clin North Am. 2012 Oct;45(5):1083-108.

6. Myssiorek D. Recurrent laryngeal nerve paralysis: anatomy and etiology. Otolaryngol Clin North Am. 2004 Feb;37(1):25-44.

7. LiY, Huang S, Zealear D. An implantable system for in vivo chronic electromyographic study in the larynx. Muscle Nerve. 2017 May; 55(5):706-14.

8. Sapundzhiev N, Lichtenberger G, Eckel HE, Friedrich G, Zenev I, Toohill RJ, et al. Surgery of adult bilateral vocal fold paralysis in adduction: history and trends. Eur Arch Otorhinolaryngol. 2008 Dec;265(12):1501-14.

9. Young VN, Rosen CA. Arytenoid and posterior vocal fold surgery for bilateral vocal fold immobility. Curr Opin Otolaryngol Head Neck Surg. 2011 Dec;19(6):422-7.

10. Gilony D, Gilboa D, Blumstein T, Murad H,Talmi YP, Kronenberg J, et al. Effects of tracheostomy on well-being and body-image perceptions. Otolaryngol Head Neck Surg. 2005 Sep;133(3):366-71.

11. DeSanto LW, Olsen KD, Perry WC, Rohe DE, Keith RL. Quality of life after surgical treatment of cancer of the larynx. Ann Otol Rhinol Laryngol. 1995 Oct;104(10 Pt 1):763-9.

12. Naunheim MR, Song PC, Franco RA, Alkire BC, Shrime MG. Surgical management of bilateral vocal fold paralysis: a cost-effectiveness comparison of two treatments. Laryngoscope. 2017 Mar;127 (3):691-7.

13. Cheung NH, Napolitano LM. Tracheostomy: epidemiology, indications, timing, technique, and outcomes. Respir Care. 2014 Jun;59 (6):895-915.

14. Newman MH,WorkWP.Arytenoidectomy revisited. Laryngoscope. 1976 Jun;86(6):840-9.

15. Woodman D. A modification of the extralaryngeal approach to arytenoidectomy for bilateral abductor paralysis. Arch Otolaryngol. 1946 Jan;43:63-5.

16. Helmus C. Microsurgical thyrotomy and arytenoidectomy for bilateral recurrent laryngeal nerve paralysis. Laryngoscope. 1972 Mar; 82(3):491-503.

17. Downey WL, Kennon WG Jr. Laryngofissure approach for bilateral 
abductor paralysis. Arch Otolaryngol. 1968 Nov;88(5):513-7.

18. Pearlman SJ, Killian EW.Thyrotomy approach for arytenoidectomy in bilateral abductor paralysis of the vocal cords. Ann Otol Rhinol Laryngol. 1953 Mar;62(1):207-12.

19. ThornellWC.A new intralaryngeal approach in arytenoidectomy in bilateral abductor paralysis of the vocal cords; report of three cases. Arch Otolaryngol. 1949 Nov;50(5):634-9.

20. Whicker JH, Devine KD. Long-term results of Thornell arytenoidectomy in the surgical treatment of bilateral vocal cord paralysis. Laryngoscope. 1972 Jul;82(7):1331-6.

21. de Campora E, Camaioni A, Corradini C, D’Agnone N, Calabrese $\mathrm{V}$, Croce A.Thornell's approach for arytenoidectomy in the surgical treatment of bilateral abductor paralysis; personal experience and results. J Laryngol Otol. 1985 Apr;99(4):379-82.

22. Maurizi M, Paludetti G, Galli J, Cosenza A, Di Girolamo S, Ottaviani F. CO2 laser subtotal arytenoidectomy and posterior true and false cordotomy in the treatment of post-thyroidectomy bilateral laryngeal fixation in adduction. Eur Arch Otorhinolaryngol. 1999; 256(6):291-5.

23. Ossoff RH, Sisson GA, Duncavage JA, Moselle HI, Andrews PE, McMillanWG. Endoscopic laser arytenoidectomy for the treatment of bilateral vocal cord paralysis. Laryngoscope. 1984 Oct;94(10): 1293-7.

24. Ossoff RH, Karlan MS, Sisson GA. Endoscopic laser arytenoidectomy. Lasers Surg Med. 1983;2(4):293-9.

25. Remacle M, Lawson G, Mayne A, Jamart J. Subtotal carbon dioxide laser arytenoidectomy by endoscopic approach for treatment of bilateral cord immobility in adduction. Ann Otol Rhinol Laryngol. 1996 Jun;105(6):438-45.

26. Sato K, Umeno H, Nakashima T. Laser arytenoidectomy for bilateral median vocal fold fixation. Laryngoscope. 2001 Jan;111(1): 168-71.

27. Crumley RL. Endoscopic laser medial arytenoidectomy for airway management in bilateral laryngeal paralysis. Ann Otol Rhinol Laryngol. $1993 \mathrm{Feb}$;102(2):81-4.

28. Hillel AT, Giraldez L, Samad I, Gross J, Klein AM, Johns MM 3rd. Voice outcomes following posterior cordotomy with medial arytenoidectomy in patients with bilateral vocal fold immobility. JAMA Otolaryngol Head Neck Surg. 2015 Aug;141(8):728-32.

29. Yilmaz T, Suslu N, Atay G, Ozer S, Gunaydın RO, Bajin MD. Comparison of voice and swallowing parameters after endoscopic total and partial arytenoidectomy for bilateral abductor vocal fold paralysis: a randomized trial. JAMA Otolaryngol Head Neck Surg. 2013 Jul;139(7):712-8.

30. Yilmaz T, Altuntas OM, Suslu N, Atay G, Ozer S, Kuscu O, et al.Total and partial laser arytenoidectomy for bilateral vocal fold paralysis. Biomed Res Int. 2016;2016:3601612.

31. Googe B, Nida A, Schweinfurth J. Coblator arytenoidectomy in the treatment of bilateral vocal cord paralysis. Case Rep Otolaryngol. 2015;2015:487280.

32. Dennis DP, Kashima H. Carbon dioxide laser posterior cordectomy for treatment of bilateral vocal cord paralysis. Ann Otol Rhinol Laryngol. 1989 Dec;98(12 Pt 1):930-4.

33. Wassermann K, Mathen F, Eckel HE. Concurrent glottic and tracheal stenoses: restoration of airway continuity in end-stage malignant disease. Ann Otol Rhinol Laryngol. 2001 Apr;110(4):349-55.

34. Pia F, Pisani P, Aluffi P. CO(2) laser posterior ventriculocordectomy for the treatment of bilateral vocal cord paralysis. Eur Arch Otorhinolaryngol. 1999;256(8):403-6.

35. Eckel HE, Thumfart M, Wassermann K, Vossing M, Thumfart WF. Cordectomy versus arytenoidectomy in the management of bilateral vocal cord paralysis. Ann Otol Rhinol Laryngol. 1994 Nov; 103(11):852-7.

36. Szakacs L, Sztano B, Matievics V, Bere Z, Bach A, Castellanos PF, et al. A comparison between transoral glottis-widening techniques for bilateral vocal fold immobility. Laryngoscope. 2015 Nov;125 (11):2522-9.

37. LiY, Pearce EC, Mainthia R,Athavale SM, Dang J,Ashmead DH, et al. Comparison of ventilation and voice outcomes between unilateral laryngeal pacing and unilateral cordotomy for the treatment of bilateral vocal fold paralysis. ORL J Otorhinolaryngol Relat Spec. 2013;75(2):68-73.

38. Sessions DG, Ogura JH, Heeneman H. Surgical management of bilateral vocal cord paralysis. Laryngoscope. 1976 Apr;86(4):559-66.

39. Damrose EJ. Suture laterofixation of the vocal fold for bilateral vocal fold immobility. Curr Opin Otolaryngol Head Neck Surg. 2011 Dec;19(6):416-21.

40. Lichtenberger G. Comparison of endoscopic glottis-dilating operations. Eur Arch Otorhinolaryngol. 2003 Feb;260(2):57-61.

41. Jatzko GR, Lisborg PH, Muller MG, Wette VM. Recurrent nerve palsy after thyroid operations: principal nerve identification and a literature review. Surgery. 1994 Feb;115(2):139-44.

42. Ejnell H, Bake B, Hallen O, Lindstrom J, Maringnsson I, Stenborg R. A new simple method of laterofixation and its effects on orolaryngeal airway resistance and fonation. Acta Otolaryngol. 1982; 93(suppl 386):196-7.

43. Ejnell H, Mansson I, Hallen O, Bake B, Stenborg R, Lindstrom J. A simple operation for bilateral vocal cord paralysis. Laryngoscope. 1984 Jul;94(7):954-8.

44. Gandhi S, Bidaye RR, Bansal D. Suture lateralization for bilateral vocal fold immobility: a review of various techniques. J Laryngol Voice. 2016;6(1):1-6.

45. Lichtenberger G. Endo-extralaryngeal needle carrier instrument. Laryngoscope. 1983 Oct;93(10):1348-50.

46. Remsen K, Lawson W, Patel N, Biller HF. Laser lateralization for bilateral vocal cord abductor paralysis. Otolaryngol Head Neck Surg. 1985 Oct;93(5):645-9.

47. Lichtenberger G. Reversible immediate and definitive lateralization of paralyzed vocal cords. Eur Arch Otorhinolaryngol. 1999;256(8): 407-11.

48. Rovo L, Jori J, Ivan L, Brzozka M, Czigner J. "Early" vocal cord laterofixation for the treatment of bilateral vocal cord immobility. Eur Arch Otorhinolaryngol. 2001 Dec;258(10):509-13.

49. Mathur NN, Kumar S, Bothra R. Simple method of vocal cord lateralization in bilateral abductor cord paralysis in paediatric patients. Int J Pediatr Otorhinolaryngol. 2004 Jan;68(1):15-20.

50. Ejnell H,Tisell LE. Acute temporary laterofixation for treatment of bilateral vocal cord paralyses after surgery for advanced thyroid carcinoma. World J Surg. 1993 Mar-Apr;17(2):277-81.

51. Jori J, Rovo L, Czigner J. Vocal cord laterofixation as early treatment for acute bilateral abductor paralysis after thyroid surgery. Eur Arch Otorhinolaryngol. 1998;255(7):375-8.

52. Lichtenberger G. Reversible lateralization of the paralyzed vocal cord without tracheostomy. Ann Otol Rhinol Laryngol. 2002 Jan; 111(1):21-6.

53. Woodson G, Weiss T. Arytenoid abduction for dynamic rehabilitation of bilateral laryngeal paralysis. Ann Otol Rhinol Laryngol. 2007 Jul;116(7):483-90.

54. Woodson G. Arytenoid abduction for bilateral vocal fold immobility. Curr Opin Otolaryngol Head Neck Surg. 2011 Dec;19(6):42833.

55. Kirchner FR. Endoscopic lateralization of the vocal cord in abductor paralysis of the larynx. Laryngoscope. 1979 Nov;89(11):177983.

56. Nawka T, Sittel C, Gugatschka M, Arens C, Lang-Roth R, Wittekindt $C$, et al. Permanent transoral surgery of bilateral vocal fold paralysis: a prospective multi-center trial. Laryngoscope. 2015 Jun; 125(6):1401-8. 
57. Ezzat WF, Shehata M, Kamal I, Riad MA. Adjustable laterofixation of the vocal fold in bilateral vocal fold paralysis. Laryngoscope. 2010 Apr;120(4):731-3.

58. Crumley RL. Phrenic nerve graft for bilateral vocal cord paralysis. Laryngoscope. 1983 Apr;93(4):425-8.

59. Marina MB, Marie JP, Birchall MA. Laryngeal reinnervation for bilateral vocal fold paralysis. Curr Opin Otolaryngol Head Neck Surg. 2011 Dec;19(6):434-8.

60. Miehlike A. Rehabilitation of vocal cord paralysis: studies using the vagus recurrent bypass anastomosis, type ramus posterior shunt. Arch Otolaryngol. 1974 Dec;100(6):431-41.

61. Li M, Chen S, Zheng H, Chen D, Zhu M,Wang W, et al. Reinnervation of bilateral posterior cricoarytenoid muscles using the left phrenic nerve in patients with bilateral vocal fold paralysis. PLoS One. 2013 Oct;8(10):e77233.

62. Tucker HM. Human laryngeal reinnervation: long-term experience with the nerve-muscle pedicle technique. Laryngoscope. 1978 Apr;88(4):598-604.

63. Tucker HM. Human laryngeal reinnervation. Laryngoscope. 1976 Jun;86(6):769-79.

64. Zealear DL, Dedo HH. Control of paralyzed axial muscles by electrical stimulation. Trans Sect Otolaryngol Am Acad Ophthalmol Otolaryngol. 1977 Mar-Apr;84(2):310.

65. Obert PM, Young KA, Tobey DN. Use of direct posterior cricoarytenoid stimulation in laryngeal paralysis. Arch Otolaryngol. 1984 Feb;110(2):88-92.

66. Zealear DL, Rainey CL, Herzon GD, Netterville JL, Ossoff RH. Electrical pacing of the paralyzed human larynx. Ann Otol Rhinol Laryngol. 1996 Sep;105(9):689-93.

67. Broniatowski M, Kaneko S, Jacobs G, Nose Y,Tucker HM. Laryngeal pacemaker: II. electronic pacing of reinnervated posterior cricoarytenoid muscles in the canine. Laryngoscope. 1985 Oct;95(10): 1194-8.

68. Herzon GD, Zealear DL. Use of an electronic laryngeal implant to restore glottic function in patients with bilateral vocal cord paralysis. Cancer Focus. 1986;8(1-2):45-8.

69. Nomura K, Kunibe I, Katada A, Wright CT, Huang S, Choksi Y, et al. Bilateral motion restored to the paralyzed canine larynx with implantable stimulator. Laryngoscope. 2010 Dec;120(12):2399409.

70. Zealear DL, Kunibe I, Nomura K, Billante C, Singh V, Huang S, et al. Rehabilitation of bilaterally paralyzed canine larynx with implantable stimulator. Laryngoscope. 2009 Sep;119(9):1737-44.

71. Zealear DL, Billante CR, Courey MS, Netterville JL, Paniello RC, Sanders I, et al. Reanimation of the paralyzed human larynx with an implantable electrical stimulation device. Laryngoscope. 2003 Jul;113(7):1149-56.

72. Mueller AH, Hagen R, Pototschnig C, Foerster G, Grossmann W, Baumbusch K, et al. Laryngeal pacing for bilateral vocal fold paralysis: voice and respiratory aspects. Laryngoscope. 2016 Dec 10 [Epub]. https://doi.org/10.1002/lary.26428.

73. Mueller AH, Hagen R, Foerster G, Grossmann W, Baumbusch K, Pototschnig C. Laryngeal pacing via an implantable stimulator for the rehabilitation of subjects suffering from bilateral vocal fold paralysis: a prospective first-in-human study. Laryngoscope. 2016 Aug;126(8):1810-6.

74. Ongkasuwan J, Courey M. The role of botulinum toxin in the management of airway compromise due to bilateral vocal fold paralysis. Curr Opin Otolaryngol Head Neck Surg. 2011 Dec;19(6):444-8.

75. Scott AB. Botulinum toxin injection into extraocular muscles as an alternative to strabismus surgery. Ophthalmology. 1980 Oct;87(10): 1044-9.

76. Zealear DL, Billante CR, Courey MS, Sant'Anna GD, Netterville JL. Electrically stimulated glottal opening combined with adductor muscle botox blockade restores both ventilation and voice in a patient with bilateral laryngeal paralysis. Ann Otol Rhinol Laryngol. 2002 Jun;111(6):500-6.

77. Marie JP, Navarre I, Lerosey Y, Magnier P, Dehesdin D, Andrieu Guitrancourt J. Bilateral laryngeal movement disorder and synkinesia: value of botulism toxin: apropos of a case. Rev Laryngol Otol Rhinol (Bord). 1998;119(4):261-4.

78. Ekbom DC, Garrett CG, Yung KC, Johnson FL, Billante CR, Zealear DL, et al. Botulinum toxin injections for new onset bilateral vocal fold motion impairment in adults. Laryngoscope. 2010 Apr;120 (4):758-63.

79. Tamaki H, Yotani K, Ogita F, Sugawara K, Kirimto H, Onishi H, et al. Effect of electrical stimulation-induced muscle force and streptomycin treatment on muscle and trabecular bone mass in earlystage disuse musculoskeletal atrophy. J Musculoskelet Neuronal Interact. 2015 Sep;15(3):270-8.

80. Hu L, Klein JD, Hassounah F, Cai H, Zhang C, Xu P, et al. Low-frequency electrical stimulation attenuates muscle atrophy in CKD: a potential treatment strategy. J Am Soc Nephrol. 2015 Mar;26(3): 626-35.

81.Willand MP, Holmes M, Bain JR, de Bruin H, Fahnestock M. Sensory nerve cross-anastomosis and electrical muscle stimulation synergistically enhance functional recovery of chronically denervated muscle. Plast Reconstr Surg. 2014 Nov;134(5):736e-745e.

82. Williams HB. The value of continuous electrical muscle stimulation using a completely implantable system in the preservation of muscle function following motor nerve injury and repair: an experimental study. Microsurgery. 1996;17(11):589-96.

83. Cheetham J, Perkins JD, Jarvis JC, Cercone M, Maw M, Hermanson JW, et al. Effects of functional electrical stimulation on denervated laryngeal muscle in a large animal model. Artif Organs. 2015 Oct;39(10):876-85.

84. Zealear DL, Billante CR, Chongkolwatana C, Rho YS, Hamdan AL, Herzon GD. The effects of chronic electrical stimulation on laryngeal muscle physiology and histochemistry. ORL J Otorhinolaryngol Relat Spec. 2000 Mar-Apr;62(2):81-6.

85. Gharib NM, Aboumousa AM, Elowishy AA, Rezk-Allah SS, Yousef FS. Efficacy of electrical stimulation as an adjunct to repetitive task practice therapy on skilled hand performance in hemiparetic stroke patients: a randomized controlled trial. Clin Rehabil. 2015 Apr;29 (4):355-64.

86. Zealear DL, Billante CL, Chongkolwatana C, Herzon GD. The effects of chronic electrical stimulation on laryngeal muscle reinnervation. ORL J Otorhinolaryngol Relat Spec. 2000 Mar-Apr;62(2): 87-95.

87. Zealear DL, Rodriguez RJ, Kenny T, Billante MJ, Cho Y, Billante $\mathrm{CR}$, et al. Electrical stimulation of a denervated muscle promotes selective reinnervation by native over foreign motoneurons. J Neurophysiol. 2002 Apr;87(4):2195-9.

88. Zealear DL, Mainthia R, LiY, Kunibe I, Katada A, Billante C, et al. Stimulation of denervated muscle promotes selective reinnervation, prevents synkinesis, and restores function. Laryngoscope. 2014 May;124(5):E180-7.

89. Bijangi-Vishehsaraei K, Blum K, Zhang H, Safa AR, Halum SL. Microarray analysis gene expression profiles in laryngeal muscle after recurrent laryngeal nerve injury. Ann Otol Rhinol Laryngol. 2016 Mar;125(3):247-56.

90. Heavner SB, Rubin AD, Fung K, Old M, Hogikyan ND, Feldman EL. Dysfunction of the recurrent laryngeal nerve and the potential of gene therapy. Ann Otol Rhinol Laryngol. 2007 Jun;116(6):441-8.

91. Rubin A, Mobley B, Hogikyan N, Bell K, Sullivan K, Boulis N, et al. Delivery of an adenoviral vector to the crushed recurrent laryngeal nerve. Laryngoscope. 2003 Jun;113(6):985-9.

92. Rubin AD, Hogikyan ND, Sullivan K, Boulis N, Feldman EL. Re- 
mote delivery of rAAV-GFP to the rat brainstem through the recurrent laryngeal nerve. Laryngoscope. 2001 Nov;111(11 Pt 1):2041-5.

93. Flint PW, Shiotani A, O'Malley BW Jr. IGF-1 gene transfer into denervated rat laryngeal muscle. Arch Otolaryngol Head Neck Surg. 1999 Mar;125(3):274-9.

94. Shiotani A, O'Malley BW Jr, Coleman ME, Alila HW, Flint PW. Reinnervation of motor endplates and increased muscle fiber size after human insulin-like growth factor I gene transfer into the paralyzed larynx. Hum GeneTher. 1998 Sep;9(14):2039-47.

95. Shiotani A, Saito K, Araki K, Moro K, Watabe K. Gene therapy for laryngeal paralysis. Ann Otol Rhinol Laryngol. 2007 Feb;116(2): 115-22.

96. Saito K, Shiotani A, Watabe K, Moro K, Fukuda H, Ogawa K. Adenoviral GDNF gene transfer prevents motoneuron loss in the nucleus ambiguus. Brain Res. 2003 Feb;962(1-2):61-7.

97. Araki K, Shiotani A, Watabe K, Saito K, Moro K, Ogawa K. Adeno- viral GDNF gene transfer enhances neurofunctional recovery after recurrent laryngeal nerve injury. Gene Ther. 2006 Feb;13(4):296303.

98. Halum SL, Naidu M, Delo DM,Atala A, Hingtgen CM. Injection of autologous muscle stem cells (myoblasts) for the treatment of vocal fold paralysis: a pilot study. Laryngoscope. 2007 May;117(5):91722.

99. Dirja BT, Yoshie S, Ikeda M, Imaizumi M, Nakamura R, Otsuki K, et al. Potential of laryngeal muscle regeneration using induced pluripotent stem cell-derived skeletal muscle cells. Acta Otolaryngol. 2016;136(4):391-6.

100. Nishio N, Fujimoto Y, Suga K, Iwata Y, Toriyama K, Takanari K, et al. Autologous fat injection therapy including a high concentration of adipose-derived regenerative cells in a vocal fold paralysis model: animal pilot study. J Laryngol Otol. 2016 Oct;130(10):914-22. 